\title{
Correction to: Microstructural and Wear Behaviour of Al 6063-W Nanocomposites Developed Using Friction Stir Processing
}

\author{
L. Feroz Ali ${ }^{1}$ (1) $\cdot$ N. Kuppuswamy ${ }^{2} \cdot$ R. Soundararajan ${ }^{3} \cdot$ K. R. Ramkumar ${ }^{4} \cdot$ S. Sivasankaran ${ }^{5}$
}

Published online: 10 August 2021

(c) The Korean Institute of Metals and Materials 2021

\section{Correction to: Metals and Materials International https://doi.org/10.1007/s12540-021-01029-z}

Unfortunately, the original publication of the article contained the errors in third author's affiliation and figure 5. The correct affiliation and Fig. 5 are given in this correction.

The original article has been corrected.

The original article can be found online at https://doi.org/10.1007/ s12540-021-01029-z.

L. Feroz Ali

ferozmts@gmail.com

N. Kuppuswamy

kuppuswamynks@gmail.com

R. Soundararajan

soundararajan.mtech@gmail.com

K. R. Ramkumar

get2raam@gmail.com

S. Sivasankaran

s.udayar@qu.edu.sa; sivasankarangs1979@gmail.com

1 Department of Mechatronics Engineering, Sri Krishna College of Engineering and Technology, Coimbatore,

Tamilnadu 641008, India
2 Department of Mechanical Engineering, KIT-Kalaignar Karunanidhi Institute of Technology, Coimbatore, Tamilnadu 641402, India

3 Department of Mechanical Engineering, Sri Krishna College of Engineering and Technology, Coimbatore 641008, Tamilnadu, India

4 Department of Metallurgical and Materials Engineering, Indian Institute of Technology Madras, Chennai 600036, India

5 Department of Mechanical Engineering, College of Engineering, Qassim University, Buraidah 51452, Saudi Arabia 
Fig. 5 FESEM micrographs of: a unreinforced $\mathrm{Al} 6063$ matrix, b $\mathrm{Al} 6063-6 \mathrm{vol} \% \mathrm{~W}$, and c $\mathrm{Al}$ 6063-12 vol\% W nanocomposites

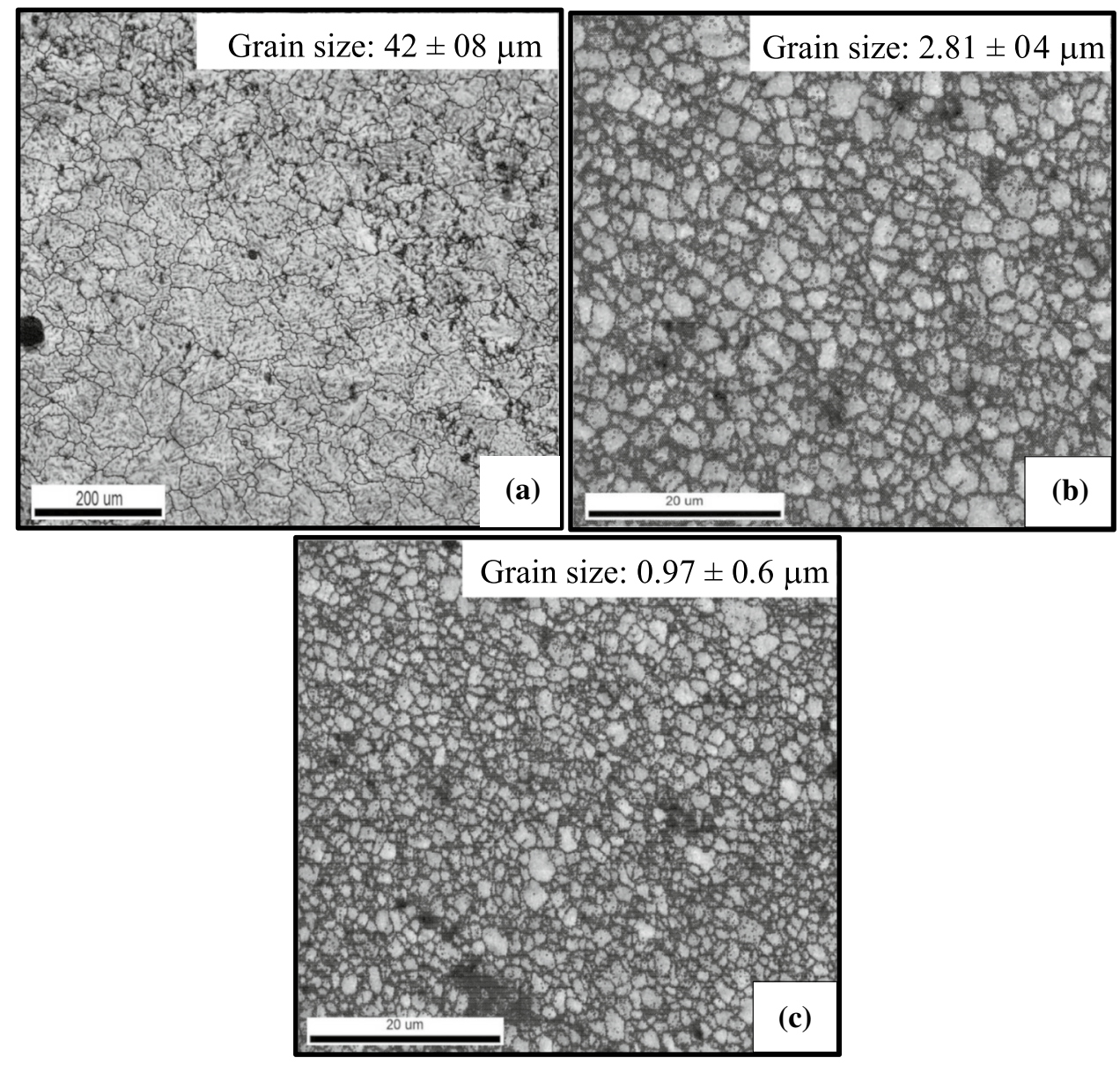

Publisher's Note Springer Nature remains neutral with regard to jurisdictional claims in published maps and institutional affiliations. 